\title{
Quadruple helix approach on education stem-based corporate social responsibility (CSR)
}

\author{
Ts. Muhammad Shafiq Shahrul Amar ${ }^{1}$,Shahrina Nordin $^{2}$, Izad Ismail $^{3}$, Syed Abdul Hadi ${ }^{4}$, and Izuan Alif Mohd \\ Arifin $^{5}$ \\ $1,4,5$ Creative Minds \\ ${ }^{2}$ Universiti Teknologi PETRONAS \\ ${ }^{3}$ Telekom Malaysia
}

\begin{abstract}
This publication outlines the rationale of the corporate social responsibility program (CSR) and employer engagement to improve career readiness for society in related demographics. The selfsustained corporate social responsibility (CSR) program explores a variety of industry partnerships possible and appropriate approaches to reduce the education gap through the digital strategy and costeffective methods. A majority of the leading industry players including technology based companies in telecommunication play a vital role not only to provide sufficient telecommunication infrastructure but foster a dynamic ecosystem for Science, Technology, Engineering and Math (STEM) education using the quadruple helix support system methods. This engagement of education based on CSR is twofold. First, a technology-based corporation program is to create a platform on reducing the digital education gap or literacy. Education CSR program served as enrichment medium on digital communication provided to rural areas in Malaysia. Second is a remarkable social impact observed in self-sustained and diversified education program models through the industry CSR approach.
\end{abstract}

\section{Introduction}

Over the years, large corporations, especially in Malaysia, engaged with communities through corporate social responsibility programs. Often society questions business operations for gaining profitability and giving back towards the welfare of society. A 2001 Nobel laureate Milton Friedman observed that "the business of business is business" as he pointed out that CSR seems to be politically influenced and seen as "window dressing" (Abdul Hamid \& Othman, 2019). Such criticisms led businesses to be more responsive to the community needs and evolved to be a more crucial strategic decision (Jellinek, 2018). CSR has increasingly attracted significant attention amongst the corporate sector, communities and other stakeholders like the local government, with increased debates and discussions amongst the academics.

A study conducted by Esa and Zahari (2017) indicated that GLCs in Malaysia has been active in CSR initiatives, especially on employee and community well-being. However, CSR initiatives by Malaysian companies are reported to be largely philanthropic in nature, which is often criticised as it is not the best practice in ensuring sustainability (Abdul Azid \& Tahir, 2019). Corporations could go beyond philanthropy and be motivated to address the social issues faced by stakeholders (Fontaine, 2013). Hence similar to Abdul Aziz and Tahir (2019), stakeholders' theory could be the underpinning guiding principle in guiding CSR initiatives by corporations. This paper hinges its framework on a quadruple helix model that involves major stakeholders for CSR initiatives.

\section{Industry - Government Support}

Malaysia's economic plan on the New Economic Model (NEM) introduced back in 2010 targeted 1.3 million jobs created particularly in Science, Technology, Engineering, and Math (STEM) related work in various industries by 2020. This focused drive on set up development policies and guidelines in infrastructure. By target set before, a realistic number of $31 \%$ growth needs to achieved on STEM- based job creation every year with support from current industry players and future foreign investment. 


\section{CSR in Malaysia}

The role of education, including schools and universities, are preparing student and community to face their future career. The upcoming 4th industrial revolution era changes the dynamic of the education system to adjust the students to aim for jobs that has not been 'created.' Fast pace influence of globalization and technology, causing industrychanging business operations faster than ever, demand new job skills, and increase productivity across demographics. The change, however, creates an education - industry gap on knowledge sharing and technology transfer A graduate that experience job mismatch, can easily affect her job satisfaction (Vichet, 2018). Large corporations such as multinational companies (MNC) and government-linked companies (GLC) are able to approach and reduce the education-industry gap through education-driven CSR programs that focus on rural areas.

A technology-based corporation such as telecommunication, aeronautics, or energy companies' business present can be measured on social impact on the business surrounding. Business influence on the balance of economic, environmental, and social imperatives thrust through social engagement. From an optics perspective, socially responsible companies project tremendous positive image to both its customers and shareholders alike, which positively affect their bottom lines (Yuan, 2011).

Socially responsible corporations tend to attract employees who are eager to make a difference in the world beyond getting a paycheck. With leading industry players mainly in technology-based operations, there is strength in numbers, where a collective employee can achieve a substantial result, which increases productivity and morale in the workplace. CSR can showcase organization employees to leverage their resources at their disposal to do good.

CSR related programs can bring direct benefits to both education and industry stakeholders including enlarging talent access and new hire comprise desired skills and competencies. CSR initiatives derive as a social investment towards society as their CSR beneficiaries. A partnership between industries can also be recognized as 'employers' are part of the strategy on diversifying investment in future skills and talents. The partnership can enhance students learning experience through exposure to the real-world application to spark their interest. Most of the education-driven CSR are able to expose students through project-based learning aligned to industry needs, internship placement and at the same time is in line with the local education system, particularly in Malaysia. For some students, CSR opportunity provides a first glimpse of what a career might entail and what problem-solving is at work.

\section{Problem Statement}

While general CSR programs can be valuable to the beneficiaries and society, industry leaders should consider developing meaningful, sustained partnerships beyond a single year of engagement. Industry leaders not only work on developing a system that is suitable to approach the basic education level but to a tailored education program that is unique and in line with industry business model to capture the essence of education-based CSR program. Robust method and approach must be applied to how best to invest limited time and resources into joint efforts. A few years back, single stakeholders were unable to develop further as a nation if the gap between the government, the industry and the education pillars is exceedingly large. Any corporation was bound to organize single stakeholder engagement as it was deemed an easy, straight forward activity that has minimal impact and an unsustainable effect. (Vishwanathan,2016) 
The corporate role in CSR plays a vital role in promoting technology in the education ecosystem. The concept of STEM learning that recently improved in the past few years addresses the lack of interest in STEM. One of the leading factors on Malaysia talent and brain drain described by Gregory Foo in his paper due to better opportunity and career growth (Foo, 2011). As the corporate CSR focus on knowledge sharing of a company technology to the public, the school students as beneficiaries will appreciate, understand and correlate most of their learning with realworld application. Knowledge sharing and technology advancement can apply to the general industry concept, patterned design, and standard. This open learning concept has developed beyond CSR, such as Hyperloop technology, proposed mode of passenger and freight transportation, first used to describe an open-source vactrain design which is jointly designed by several leading university students across the world.

Engagement on single stakeholders for education CSR has significant disadvantages on financial investment towards social impact. One single entity (referred to the corporation) has limited resources on planning and execution. The disconnection between a corporation or industry partners with other entities such as government and higher education institutions can be seen as a strong partnership, bringing more impact in the CSR program and gives higher value on its social investment in STEM education.

\section{Quadruple Helix Approach - Theoretical Background and Past Studies}

The synergy among universities, government, and industry, began and was known as the Triple Helix approach. The approach was introduced by Etzkowitz and Leydesdorff (2000). The Quadruple Helix Model extends the key player to include four major actors (Schutz, Heidingsfelder \& Schraudner, 2019). The four major actors commonly include a higher education institution (academics or researchers), industry or corporate, policy-makers or government agencies, and the society. The Quadruple Helix Model was originally developed by Elias Carayannis and David Campbell (2009), which is illustrated as follows.

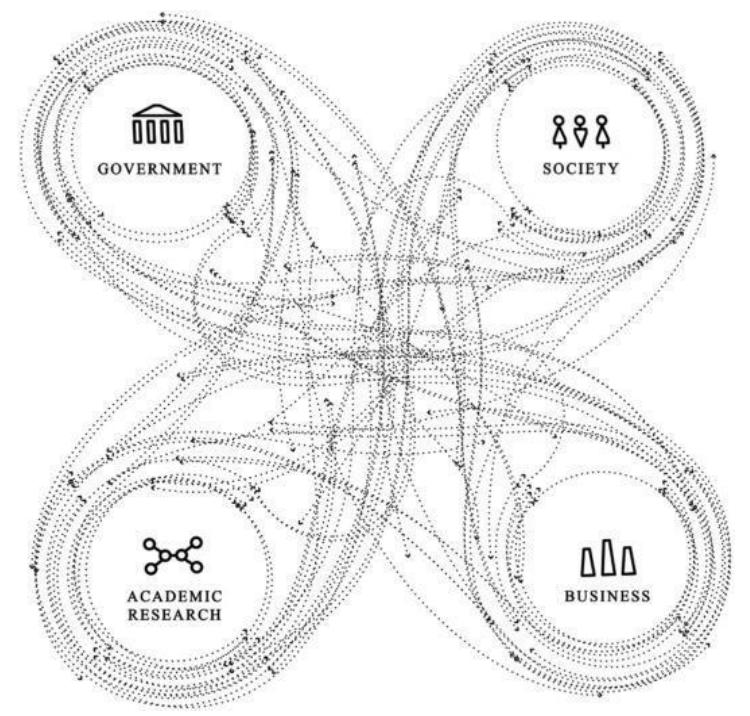

Figure 1: The Quadraple Helix Model (cited in Schutz, Heidingsfelder \& Schraudner, 2019) 
The model illustrates four core components for a successful implementation of the model which are academia, industry, government and society. The underpinning theoretical assumption is that the structure of an economy consists of the four helixes in contributing to economic development and innovations. The conceptualization is illustrated as "multi-layered, dynamic, bi- directional interactions" (Schutz, Heidingsfelder \& Schraudner, 2019). Its complex nature of collaboration poses challenges in its implementation which include coordination and integration towards a common goal.

Karmokar and Shekar (2018) discussed an outreach program using the Triple Helix model to encourage interest in Science and Technology among underrepresented youth. The initiative was to create a better understanding of science, technology, engineering and mathematics (STEM) and entrepreneurship in New Zealand that involved the government, university and industry. The initiative discussed in this current paper, however, adopted the Quadruple Helix model by extending the model to include the community. Quadruple Helix model was encouraged by the Prime Minister of Malaysia, "The future of the nation hinges on this Quadruple Helix", (The Star, 1 March 2012).

The level of awareness and the perception of technology corporation professionals on basic concepts, elements, and functions of CSR has increased significantly (Mohamed, 2019) The in- depth interview with some professionals revealed that their respondents' perception was too simplistic. Besides, it was also in contrast to the reality which was supposed to be more complicated for them. The general level of awareness and knowledge of the technology professionals on the concepts of CSR were not consistent even though the current CSR activities were admittedly commendable.

A quadruple helix approach has been tested and proven to suit organizing education CSR programs focussed on STEM and represents a bridge for the gap between industry and education (Fabio, Frey \& Marco, 2014). A corporation or technology industry player and higher education institutions act as enablers that can be the talent pipeline for company talent and run a CSR program funded by technology corporations. As mentioned by Elizaberth Feedman on talent pipeline, the skills and qualities that lead to hiring, promotions and career progression are often quite different from those that a leader needs to be successful. The process of becoming a talented leader requires time, experience, hard work and, quite often, expert assistance from a met tor or coach (Freedman, 2012). The CSR on an education platform can benefit future graduates to develop talent in line with technology corporate seek to hire future graduates.

Critical and third stakeholders are governing bodies that are relevant to the STEM education ecosystem. The related organization includes local government office, education ministry, and rural development ministry. The critical role is on mapping the right community that will bring the highest impact on the education CSR program. Education ministry plays a vital role in mapping the program into a national syllabus so CSR education can be relevant in the classroom and at the same time beneficial to corporate as program champion. The government can help to push any policies and regulations that is best for community interest and corporate partner can help shape education to be more relevant and produces future talent that is employable and possess both high technical and managerial skills. A quadruple helix approach factoring all relevant stakeholders above can be seen as a great model of STEM Education CSR further elaborate on the concept methodology below. 


\section{The Approach}

The CSR program focusing on education based approach can be emphasised on the weaker cluster of education (Lund-Thomsen). The two main areas of improvement recognized throughout Malaysia including rural areas are English language proficiencies and Science stream subjects. The core science stream subjects in STEM are Science, Technology, Engineering and Maths in single-core learning. The approach of involving the Multinational Corporations (MNC) or Governent-linked Corporations (GLC) in stepping up to push the STEM agenda is relatively new in Malaysia. STEM naturally resides within the prerogative of the Ministry (government) and the education fraternity, hence the involvement by the corporate and industry in this effort used to be uncommon. The involvement from the corporate and industry is seen as a gap mitigation initiative. STEM education is seen as highly relevant to job market demand in the industry.

Technology-based corporations in Malaysia such as in telecommunication, automotive or oil and gas industry have shown a great interest in the realm of education and nation-building as their CSR initiatives. CSR in education is very often seen as part of technology transfer and knowledge sharing from the industry to community grassroots as the beneficiaries. The industry-driven technology program through CSR can be recognized as relevant especially for the purpose of shaping the future job market and for the purpose of talent hunt. Stakeholders from the industry could play a significant role in closing the gap as per required for the future workforce.

Critical elements in CSR education can also be observed in a recent program by Telekom Malaysia Group (TM Group). The concept of CSR program that was executed involved all relevant key stakeholders. All angles are taken into consideration to ensure the program is affordable and scalable across the demographics of targeted participants. Prior to the program implementation, personnel of TM Group had engaged both appropriate external and internal stakeholders to ensure its cost- effectiveness, feasibility and that the STEM content is understandable by the targeted beneficiaries. As part of the initiative of STEM-based learning was to apply graphical steps and instructions. The English language was used in all program handouts and training manuals. However, the medium of verbal instruction and communication during the STEM CSR program was primarily Bahasa Malaysia, the participants' mother tongue and widely spoken in the country.

The beneficiaries who are mainly students within rural areas are able to understand instruction clearly and not restricted by a medium of language for the training manual provided. One of the critical steps to roll out is the mapping of the STEM education offering towards the current Malaysian education syllabus. Every STEM education program is advised by the Malaysia Ministry of Education's expert panel to authenticate each subject learned by the students. STEM programs such as robotics, 3D printing, data logging or mobile app development are subjects that are not being taught directly. Thus, the concept of learning technology through science and mathematics can be challenging. The biggest challenge in conducting a STEM-related program is in creating students' interest especially at its initial level. The concept of syllabus mapping will be more applicable once students are able to grasp the basic concept and real-world application that revolves around the techniques taught during this CSR education program.

The overall process involves four fundamental stakeholders including the corporation, government ministry and agencies, university and community (students as beneficiaries). TM Group on the CSR initiatives above tie-in closely with its education subsidiaries, Multimedia University (MMU) on content validation and program management. Most of the programs rolled out by MMU university students could lead to great visibility of the corporation as it involves the community. 


\subsection{Impact on Corporate CSR}

Corporate social responsibility (CSR) has gained increasing attention over the past decade as all the stakeholders can visibly see the impact. Some of the impacts include acceptance from government regulation to set up a few community-based initiatives. In 2019, the Ministry of Education has been adopting a STEM-based learning movement called STEM4ALL nationwide that implements three new policies shifts (NST,2019). The initiative received positive input and support from industry players to engage beneficiaries with a more significant impact. The government also launched a few tax relief programs that extend on school maintenance and trust school program for rural area schools.

Online competition and engagement can benefit back industry players on their CSR engagement (Fuller, 1999). From TM CSR program rollout for STEM, part of the sustainability program was pushed online from content on education module, competition, and online engagement. The STEM online competition by TM Group benefits its online presence by the organic reach that can increase visibility through online access.

The CSR project by TM Group has also being a benchmark for the education module to roll out in the education system for several academic subjects in schools. The project eliminates the cost of research and testing by the Ministry and uses TM Group CSR engagement results to promote more STEM-related programs in the classroom.

\section{Conclusion}

CSR has become crucial for every company in this world and the impact has been visibly seen across Malaysia. In fact, without hesitation there are many corporations which would like to have a good reputation through it as 'good will' and bring a positive impact in their business presence Most of the studies on CSR in Malaysia widely focused on the disclosure and limited studies and one time off activity omitting the important factor of sustainability and scalability. Technology-based company has unlimited potential on adapting quadruple helix approach on CSR though STEM based program. The result shows that this type of activities leads to financial performance, promoting STEM education, and funnel future talent towards their organization. 


\section{References}

Abdul Aziz, N.Z. \& Tahir, P.R. (2019). Corporate Social Responsibility Environment In Malaysia: Lessons Learned From The Effectiveness Of The Csr Programme By Axiata GROUP, International Journal of Entrepreneurship and Management Practices, 2(5): $72-$ 821

Abdul Hamid, A.K. \& Othman, Z. (2019) Corporate Social Responsibility by Malaysian and Singapore Sustainable Index Companies. International Journal of Accounting and Financial Reporting, 9(2).

Carayannis, EG, \& Campbell, DFJ (2009).“Mode 3"and“Quadruple Helix”: towards 21st century fractal innovation ecosystem. International Journal ofTechnology Management, 46(3/4), 201-234.

Esa, E., \& Zahari, A. R. (2017). Disclosure on Corporate Websites: Corporate Social Responsibility in Malaysia \& Singapore Government- Linked Companies. Journal of Technology Management and Business, 4(1), 87-95.

Etzkowitz, H. \& Leydesdorff, L. (2000), The Dynamics of Innovation: From National Systems and Mode 2 to a Triple Helix of University Industry Government Relations. Research Policy, 29, 109-123.

Jellinek, D. (2018). Historical background of corporate social responsibility. Social Responsibility Journal, 7(4).

Karmokar, S. \& Shekar, A. (2018). Outreach programmes using the Triple Helix model to encourage interest in Science and Technology among underrepresented youth. Design and Technology Education: An International Journal 23(1): 88-103.

Mohamed (2019). Roles and Challenges of Technology in Corporate Social Responsibility. The International Journal of Social Sciences and Humanities Invention. 6. 5336-5340. 10.18535/ijsshi/v6i2.10.

Battaglia, Massimo, Testa, Francesco, Bianchi, Lara, Iraldo, Fabio, Frey \& Marco. (2014). Corporate Social Responsibility and Competitiveness within SMEs of the Fashion Industry: Evidence from Italy and France. Sustainability. 6. 872-893. 10.3390/su6020872.

Star Online (1 March 2012), 'Quadruple Helix' way to innovation”. Retrieved from https://www.thestar.com.my/news/nation/2012/03/01/quadruple-helix-way-toinnovation, 20 January 2019.

Schutz, F., Heidingsfelder, M.L. \& Schraudner, M. (2019). Co-shaping the Future in Quadruple Helix Innovation Systems: Uncovering Public Preferences toward Participatory Research and Innovation, She Ji: The Journal of Design, Economics, and Innovation, 5(2), 128-146.

NST Online (20 March 2019) 'STEM Policies Need A review”. Retrieved from

https://www.nst.com.my/education/2019/03/471176/stem-policies-set-evolution

Industrial Clusters and Corporate Social Responsibility in Developing Countries: What We Know, What We Do Not Know, and What We Need to Know . / Lund-Thomsen, Peter; Lindgreen, Adam; Vanhamme, Joelle. In: Journal of Business Ethics, Vol. 133, No. 1, 2016, p. 9-24 
A. R. Ahmad Dahlan, J. Ibrahim, N. S. Aniza Binti Zakaria, I. B. Ishak, N. N. Binti Rahim and N. A. Binti Abd Malek, "eSoulKitchen program - Enhancing societal wellbeing and wealth creation for Orang Asli Community at Pos Selim, Perak," The 5th International Conference on Information and Communication Technology for The Muslim World (ICT4M), Kuching, 2014, pp. 1-6. doi: 10.1109/ICT4M.2014.7020634

Fuller, C. (1999), "Benchmarking health and safety performance through company safety competitions", Benchmarking: An International Journal, Vol. 6 No. 4, pp. 325337. https://doi.org/10.1108/14635779910297424 